\title{
CARACTERIZAÇÃO QUÍMICA PARCIAL DAS SEMENTES DE Lecythis pisonis Camb. (SAPUCAIA).
}

\author{
Maria Isabel VALLILO ${ }^{1}$, Mario TAVARES ${ }^{2}$; Sabria Aued PIMENTEL ${ }^{2}$; Elza \\ Schware Gastaldo BADOLATO², Emiko Ikejiri INOMATA ${ }^{2}$.
}

\begin{abstract}
RESUMO - Estudou-se a composição química de amêndoas do fruto da sapucaia (Lecythis pisonis Camb), provenientes da Estação Experimental de Santa Rita do Passa Quatro (SP), do Instituto Florestal de Sào Paulo. As análises quimicas foram realizadas segundo as "Normas Analiticas do Instituto Adolfo Lutz (1985). Os resultados obtidos mostraram altos teores lipidicos $(63,5 \mathrm{~g} / 100 \mathrm{~g})$, protéicos $(19,9 \mathrm{~g} / 100 \mathrm{~g})$, vitamina C $(17,1 \mathrm{mg} / 100 \mathrm{~g})$ e valor calórico de $684 \mathrm{Kcal} / 100 \mathrm{~g}$. A fração oleosa apresentou um perfil de ácido graxos e índice de iodo $(113,5)$, equivalente ao do óleo de milho comestivel, destacando-se o ácido linoléico $(48,6$ $\% \mathrm{p} / \mathrm{p}$ ) considerado como ácido graxo essencial e participante nos processos de inibição de germinação de sementes. O perfil de ácidos graxos do óleo das amêndoas de sapucaia, os teores de lipídios e de proteína foram semelhantes aos das amêndoas de castanhas-do-Pará (Bertholletia excelsa), espécie da mesma familia da sapucaia, cultivada na Amazônia. Para a determinação dos nutrientes, as amostras foram tratadas por via úmida $\left(\mathrm{H}_{2} \mathrm{SO}_{4}\right.$ e $\left.\mathrm{H}_{2} \mathrm{O}_{2}\right)$, através da radiação de microondas por sistema aberto de digestão e quantificadas por Espectrometria de Emissão Atômica com Plasma de Argônio Induzido (ICP-AES). A espécie revelou teores elevados para Na $(49,8 \mathrm{mg} / \mathrm{g}) ; \mathrm{K}(46,4 \mathrm{mg} / \mathrm{g}) ; \mathrm{B}(64,5 \mathrm{mg} / \mathrm{g}) ; \mathrm{Mn}(91,0 \mu \mathrm{g} / \mathrm{g}) ; \mathrm{Fe}(14,2 \mu \mathrm{g} / \mathrm{g})$ e Al $(4,91 \mu \mathrm{g} / \mathrm{g})$. Entretanto, o nivel de $\mathrm{Pb}$ encontrado $(0,96 \mu \mathrm{g} / \mathrm{g})$, está acima do limite máximo permitido pela legislação brasileira $(0,5 \mu \mathrm{g} / \mathrm{g})$, evidenciando uma possivel toxicidade da amostra e contaminação antrópica do local amostrado.
\end{abstract}

Palavras-chave: composição quimica; ácidos graxos; metais pesados.

\section{Partial Chemical Characterization of Lecythis pisonis Camb. (Sapucaia).}

ABSTRACT - The chemical composition of sapuacia (Lecythis pisonis Camb.) from the Santa Rita Experiment Station, São Paulo Forest Institute, Passa Quatro, São Paulo, Brazil, was studied. Proximate chemical analytical methodology followed the 'analytical methods of the Adolfo Lutz Institute, 1985;' samples were digested with $\mathrm{H}_{2} \mathrm{SO}_{4}$ and $\mathrm{H}_{2} \mathrm{O}_{2}$-foracid in a microwave and minerals determined by ICP-AES. Fats represented $63.5 \%$ and proteins $19.9 \%$ fresh weight, explaining the high energy content of $684 \mathrm{kcal} ; 17.1 \mathrm{mg} / 100 \mathrm{~g}$ of vitamin C were also observed. The fatty acid profile and iodine value (113.5) were similar to those of corn (Zea mays) oil. Linoleic acid was predominant $(48.6 \%)$; this is an essential fatty acid and has a role in loss of seed viability. Sapucaia's fatty acid profile, oil and protein contents were similar to those of Brazil nut (Bertholletia excelsa), a cultivated species of the same family. The seeds contained high concentrations of $\mathrm{Na}(49.8 \mathrm{mg} / \mathrm{g})$, $\mathrm{K}(46.5 \mathrm{mg} / \mathrm{g}), \mathrm{B}(64.5 \mathrm{mg} / \mathrm{g}), \mathrm{Mn}(19.0 \mu \mathrm{g} / \mathrm{g}), \mathrm{Fe}(14.2 \mu \mathrm{g} / \mathrm{g})$ and $\mathrm{Al}(4.91 \mu \mathrm{g} / \mathrm{g})$. The high concentration of $\mathrm{Pb}(0.96 \mu \mathrm{g} / \mathrm{g})$, above the legal Brazilian limit $(0.5 \mu \mathrm{g} / \mathrm{g})$, suggests sample toxicity and anthropogenic contamination of the plantation site.

Key words: chemical composition, fatty acids, heavy metals.

\section{INTRODUÇÃO}

Frutos e sementes de algumas espécies florestais brasileiras revelaramse, através de estudos, boas fontes de nutrientes, como por exemplo a castanha do pará (Bertholletia excelsa Humb. \& Bonpl.), nativa da Amazônia ( Cavalcante, 1996; Gutierrez et al; 1997) e o piquí ( Caryocar brasiliense Camb.),

\footnotetext{
Instituto Florestal, Divisão de Dasonomia, Seção de Madeiras e Produtos Florestais, Rua do Horto, 931, CEP 02377-000 - São Paulo, SP.

2 Instituto Adolfo Lutz, Divisão de Bromatologia e Química, Seção de Óleos, Gorduras e Condimentos, Av. Dr Arnaldo, 355, CEP 01246-902 - São Paulo, SP.
} 
coletado na região de Campo Grande, capital do Estado de Mato Grosso do Sul (Hiane et al., 1992). Entretanto, muitos outros frutos disponiveis no território brasileiro, necessitam ser pesquisados quanto à sua composição química, a fim de que os dados obtidos possam contribuir para a elaboração de tabelas de composição de alimentos e, na prática, para enriquecer a dieta da população, particularmente a de maior carência nutricional, bem como, estabelecer procedimentos de estocagem ou armazenamento, visando manter a sua viabilidade ou o seu poder de germinação.

Dados da literatura mostram que sementes com altos teores de lipídios apresentam com o tempo, perda da sua viabilidade. Este fato é comprovado por Kaloyeras et al. (1958), com sementes de Pinus, demonstrando que existe uma relação entre o desenvolvimento da rancidez do óleo fixo e a perda do poder de germinação. Mirov apud Kaloyeras et al. (1958), atribui esse fato à presença de ácidos graxos insaturados, principalmente do ácido linoléico, que se oxida nos processos bioquímicos da respiração da semente, provocando rancidez do óleo, quando armazenadas em condições normais de temperatura e de luz natural, resultando a perda do seu vigor germinativo. Goldman et al. (1986/1987) e Façanha \& Varela (1986/1987), têm chamado atenção para o fato que o poder de germinação das sementes é um fenômeno também dependente da temperatura de armazenamento.

Como fonte de matéria-prima para indústria óleoquímica sabe-se que, atualmente, tem crescido consideravelmente tanto a pesquisa quanto a produção de frutos e sementes de oleaginosas, representando $70 \%$ do total de óleos obtidos de fontes naturais que, na sua maioria, são absorvidos pela indústria de alimentos (Freire et al., 1996).

Neste contexto, apresenta-se a semente de sapucaia, Lecythis pisonis Camb, que é popularmente utilizada como parte comestivel do fruto no interior do Brasil, principalmente nos Estados de Pernambuco até São Paulo e na Amazônia, supondo-se originária da parte central leste desta região (Cavalcante, 1996; Mori \& Prance, 1990). No entanto, pouco se sabe sobre a composição química e o valor nutricional, o que motivou o presente estudo.

Dando continuidade ao trabalho já realizado por Vallilo et al. (1990), com outra espécie florestal, o cumbarú, o presente trabalho teve o objetivo de caracterizar a semente de sapucaia através da determinação da composição centesimal, de ácidos graxos e de micro e macronutrientes, visando: a) a possível utilização da sapucaia como fonte alternativa para fins alimentícios ou energéticos e, b) os processos de armazenamento, a fim de atender programas de plantio e reflorestamentos.

\section{MATERIAL E MÉTODOS}

\section{Descrição da espécie}

A espécie Lecythis pisonis Camb, pertencente a familia botânica Lecythidaceae é facilmente encontrada na Mata Pluvial Atlântica, desde os Estados do Ceará e Pernambuco até 
o Rio de Janeiro e São Paulo, bem como alguns exemplares também foram encontrados na Amazônia (Mori \& Prance, 1990; Cavalcante, 1996). Seus frutos na forma de cápsulas, conhecida como pixidio, podem atingir até $50 \mathrm{~cm}$ de diâmetro e pesar até $2 \mathrm{Kg}$. (Fig 1). Floresce e frutifica entre o inverno e primavera no hemisfério Sul. As sementes contendo as amêndoas são grandes e se propagam através da dispersão zoocórica, principalmente por macacos (Mori \& Prance, 1990; Aguiar et al., 1993). Os frutos quando maduros são abertos espontaneamente, liberando as sementes. As exsicatas dessa espécie estão depositadas no Herbário D. Bento Pickel, do Instituto Florestal de São Paulo.

\section{Procedência}

Os frutos da sapucaia foram colhidos da árvore em agosto de 1995, por técnicos do Instituto Florestal, na Estação Experimental de Santa Rita do Passa Quatro do Instituto Florestal de São Paulo, localizada no Município de mesmo nome. Em seguida, foram transferidos à Seção de Silvicultura deste instituto, para o beneficiamento, teste de germinação e posterior armazenamento em câmara fria (temperatura de $\pm 5^{\circ} \mathrm{C}$ ). Foram beneficiadas $6,5 \mathrm{Kg}$ de sementes.

\section{Tratamento das amostras}

As amêndoas foram retiradas manualmente das sementes $(1 \mathrm{~kg})$, com o auxílio de morsa e espátulas e, divididas em sub-amostras contendo 20 unidades cada. Em seguida, foram trituradas e homogeneizadas através de um multiprocessador doméstico para análise nos laboratórios dos Institutos Florestal e Adolfo Lutz de São Paulo.

\section{Métodos}

$\mathrm{O}$ teste de germinação seguiu as "Regras para Análise de Sementes"(Ministério da Agricultura, 1992) indicando um teor de germinação para essas amostras de $26 \%$.

A composição centesimal (umidade, cinzas, extrato etéreo e proteina), a conversão dos ácidos graxos em ésteres metílicos e a determinação das vitaminas B1, B2 e $\mathrm{PP}$ foram realizadas conforme os métodos descritos nas "Normas Analíticas do Instituto Adolfo Lutz" (Instituto Adolfo Lutz, 1985), sendo os carboidratos calculados por diferença. Foi empregado o fator 6,25 para conversão de nitrogênio em proteina.

A análise dos ésteres metílicos dos ácidos graxos foi efetuada usando-se um cromatógrafo a gás, marca CG 500 , com detector de ionização de chama, acoplado a um integrador (CG 300). Os componentes foram separados em coluna capilar de sílica fundida Carbowax $20 \mathrm{M}$, de 30 metros com diâmetro interno de $0,25 \mathrm{~mm}$ e espessura do filme de $0,25 \mathrm{~mm}$. Foram observados as seguintes temperaturas de operação: injetor, $230^{\circ} \mathrm{C}$; detector, $240^{\circ} \mathrm{C}$; coluna, programada de 100 a $230^{\circ} \mathrm{C}$ $\left(10^{\circ} \mathrm{C} / \mathrm{min}\right.$.). $\mathrm{O}$ gás de arraste empregado foi o hidrogênio com fluxo de $0,8 \mathrm{~mL} / \mathrm{min}$. Razão de divisão da amostra: 1:100.

A identificação dos ácidos graxos foi feita por comparação com os respectivos padrões individuais e, a quantificação, por normalização da 

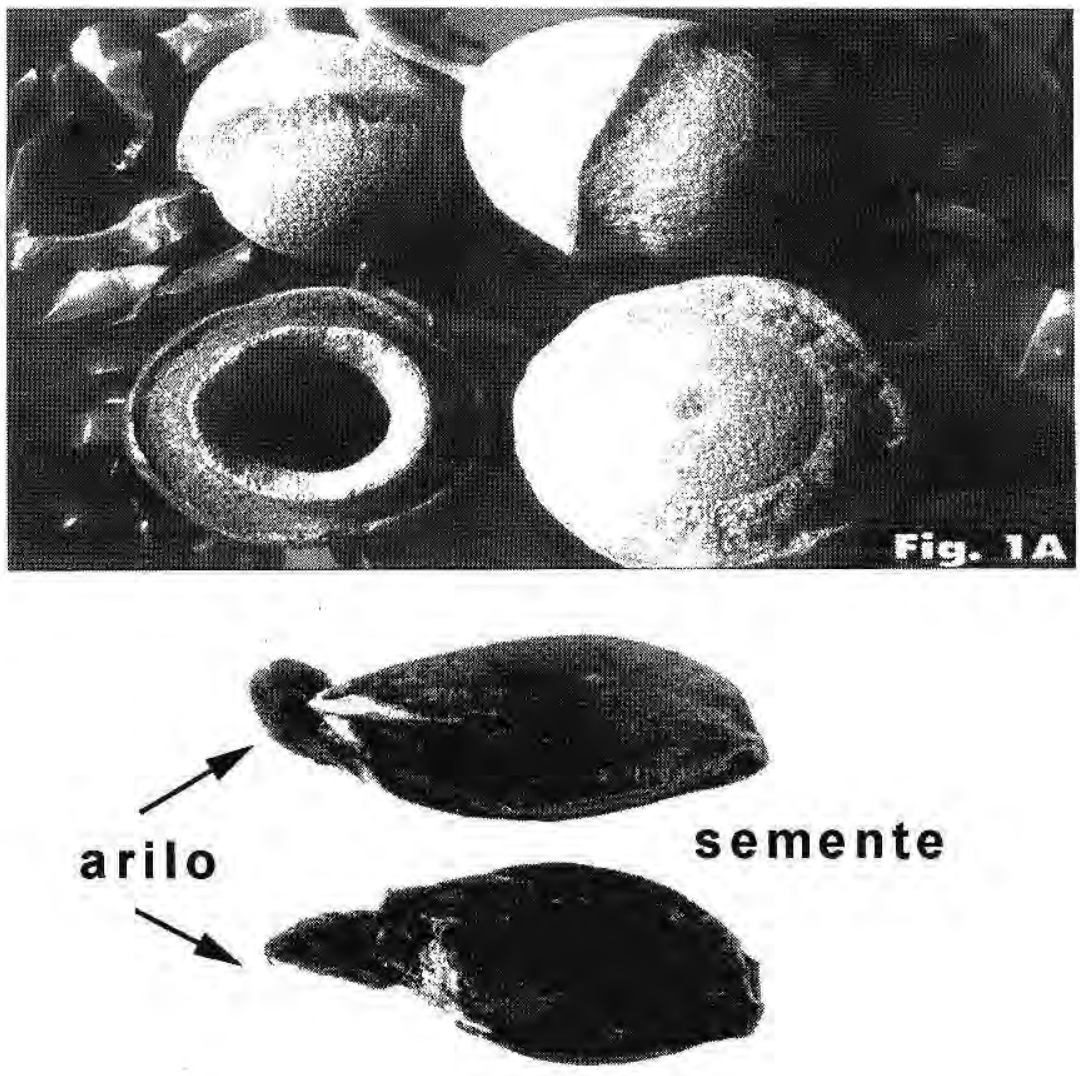

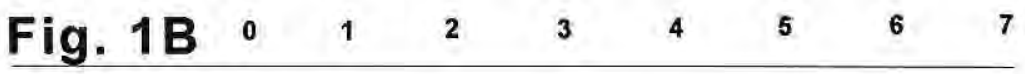

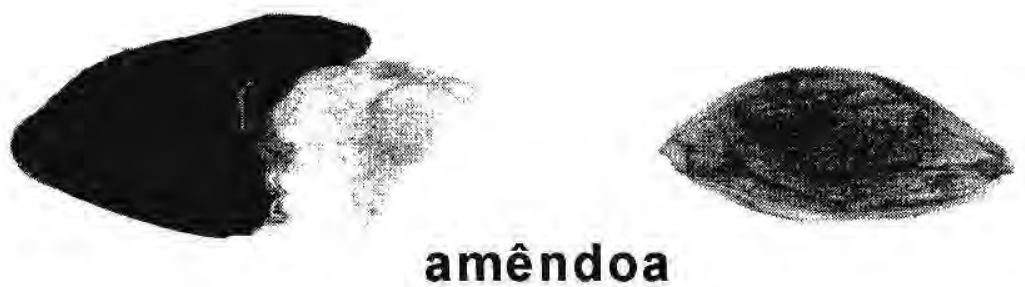

Fig. 1C

Figura 1. Aspectos do fruto de Lecythis pisonis Camb. (sapucaia).
(A) inteiros e abertos
B) sementes com arilo
C) amêndoas 
área de cada pico.

$\mathrm{O}$ teor de vitamina $\mathrm{C}$ foi determinado por redução de ions cúpricos segundo Contreras-Guzman et al. (1984), enquanto que o valor calórico foi calculado pelos fatores de Atwater, ou seja, proteína $(4,0)$; carboidratos $(4,0)$ e extrato etéreo $(9,0)$ segundo De Angelis (1977).

$\mathrm{O}$ indice de iodo da fração oleosa (extrato etéreo) foi calculado pelo método da A.O.C.S. Cd 1c-85 (AMERICAN OIL CHEMISTS' SOCIETY, 1990).

Para a determinação dos macros e micronutrientes, as amostras foram tratadas por via úmida, no laboratório de Espectrometria de Emissão Atômica, do Instituto de Química da USP, utilizando-se a radiação de microondas em sistema aberto de digestão, segundo método indicado no manual do aparelho (MANUAL RAPID DIGESTION SYSTEM MX 350 SPEX, 1991), sob as seguintes condições de operação:

$1^{\text {a }}$ ETAPA: na amostra $(0,5 \mathrm{~g})$ foi adicionada $10,0 \mathrm{ml}$ de $\mathrm{H}_{2} \mathrm{SO}_{4}$ conc. e 5,0 $\mathrm{ml} \mathrm{H}_{2} \mathrm{O}_{2}$ a $30 \%$ em volume. Aplicou-se a potência de $60 \mathrm{~W}$ por 5 minutos.

$2^{\mathrm{a}}$ ETAPA: na solução obtida na $1^{\mathrm{a}}$ etapa, adicionou-se mais $5,0 \mathrm{ml} \mathrm{de} \mathrm{H}_{2} \mathrm{O}_{2}$ a $30 \% \mathrm{v} / \mathrm{v}$, nas mesmas condições de tempo e potência anteriormente descritas;

$3^{\text {a }}$ ETAPA: adicionou-se mais $2,0 \mathrm{ml} \mathrm{H}_{2} \mathrm{O}_{2}$ no solubilizado obtido na $2^{\mathrm{a}}$ etapa, submetendo a solução à aquecimento na potência de $90 \mathrm{~W}$ por 5 minutos.

A solução obtida na $3^{\text {a }}$ etapa foi transferida para balão volumétrico de 50,0 $\mathrm{mL}$ e, completado o volume com água desionizada. A solução apresentou-se limpida com coloração amarelo clara, com a qual quantificou-se os elementos inorgânicos.

\section{Determinação dos elementos químicos}

Os elementos químicos $(\mathrm{Mg}, \mathrm{Ca}$, $\mathrm{Na}, \mathrm{K}, \mathrm{B}, \mathrm{As}, \mathrm{Fe}, \mathrm{Mn}, \mathrm{Pb}, \mathrm{Se}, \mathrm{Al}$ e $\mathrm{Sn}$ ) foram caracterizados e quantificados nas amostras solubilizadas, pela técnica da Espectrometria de Emissão Atômica acoplada ao Plasma Indutivamente (ICP-AES), operando a potência de $1,2 \mathrm{Kw}$, fluxo de argônio refrigerante, auxiliar e carregador de $12 \mathrm{l} / \mathrm{min}, 1,2 \mathrm{~L} / \mathrm{min}$ e $1,0 \mathrm{ml} / \mathrm{min}$, respectivamente $\mathrm{e}$, a velocidade de introdução da amostra de $1,5 \mathrm{ml} / \mathrm{min}$. A leitura dos elementos foi feita na altura de observação de $12 \mathrm{~mm}$ acima da bobina de cobre do ICP - AES, nos seguintes comprimentos de onda: $(\lambda s)$ em nm: $\lambda_{\text {As }}=188,979 ; \lambda_{\mathrm{Ca}}=317,940$; $\lambda_{\mathrm{Mg}}=285,210 ; \lambda_{\mathrm{Fe}}=239,562 ; \lambda_{\mathrm{Al}}=236,902$; $\lambda_{\mathrm{Mn}}=257,615 ; \lambda_{\mathrm{Pb}}=283,307 ; \lambda_{\mathrm{B}}=249,766$; $\lambda_{\mathrm{Se}}=196,020 ; \lambda_{\mathrm{Sn}}=189,926 ; \lambda_{\mathrm{Na}}=589,995 \mathrm{e}$ $\lambda_{\mathrm{K}}=766,491$.

Todas as análises foram efetuadas em duplicatas, à exceção da composição em ácidos graxos (com cinco repetições) e dos macro e micronutrientes (em triplicatas).

\section{RESULTADOS E DISCUSSÃO}

A composição centesimal das amêndoas do fruto da sapucaia encontra-se descrita na Tabela 1 , onde pode-se observar o elevado teor do extrato etéreo $(63,03 \%)$, com a maior parte representada por lipidios. Este dado se aproxima aos encontrados na literatura $(62,60 \%)$, o que dá a esta 
semente o caráter de oleaginosa. Por outro lado, nas amêndoas, os açúcares totalizaram apenas $8,28 \%$ da composição total e as proteinas, $19,86 \%$, tornando-as muito promissoras como fonte protéica. Todos esses valores estão bem próximos daqueles apresentados em tabela de composição de alimentos para a espécie

Tabela 1. Composição química e valor calórico das amêndoas de Lecythis pisonis Camb. (sapucaia).

\begin{tabular}{lcc}
\hline Composição & Teores & Ret." \\
\hline & $\mathrm{g} / 100 \mathrm{~g}$ & $\mathrm{~g} / 100 \mathrm{~g}$ \\
Umidade & 4,92 & \\
Cinzas & 3,91 & \\
Extrato etéreo & 63,03 & 62,60 \\
Proteínas & 19,86 & 22,20 \\
Carboidratos* & 8,28 & 10,20 \\
Vitaminas & $\mathrm{mg} / 100 \mathrm{~g}$ \\
B1 & 0,31 \\
B2 & 0,27 \\
C & 17,10 \\
PP (niacina) & não encontrado \\
Valor calórico & Kcal/100g \\
\multicolumn{3}{c}{684,00} \\
\hline
\end{tabular}

- obtidos por diferença

* - Franco, G.(1992).

Lecythis lanceolata, L.(Franco, 1992).

Tanto os lipidios quanto as proteínas, foram os responsáveis pelo elevado teor calórico da semente $(684 \mathrm{Kcal} / 100 \mathrm{~g})$. As pequenas diferenças encontradas, a menos, nos teores de açucares e proteínas, quando comparadas com as encontradas na literatura, deve-se provavelmente ao teor de maturação dos frutos que compuseram as amostras analisadas ou ao protocolo analítico utilizado na determinação dos mesmos.

A Tabela 2 mostra a composição em ácidos graxos das amêndoas estudadas, bem como a faixa de valores aplicada pelo Codex Alimentarius para óleo de milho comestivel (CODEX ALIMENTARIUS COMMISSION, 1993).

$\mathrm{O}$ ácido linoléico (C18:2), ácido graxo essencial, predominou no óleo da semente da sapucaia $(48,6 \%)$, vindo a seguir o oléico (C18:1). O teor de proteina e lipidios da semente da sapucaia e a composição de ácidos graxos do óleo da amêndoa, foram semelhantes aos encontrados para a castanha-do-Pará (Bertholletia excelsa), espécie da mesma familia da sapucaia

Tabela 2. Composiçâo de ácidos graxos do óleo das amêndoas de Lecythis pisonis Camb. (Sapucaia).

\begin{tabular}{lccccccc}
\hline $\begin{array}{c}\text { Ácido } \\
\text { graxos }\end{array}$ & \multicolumn{7}{c}{ Amostras N $^{\circ}$} \\
C16:0 & 1 & 2 & 3 & 4 & 5 & média & Ref $^{*}$ \\
C16:1 & 12,6 & 13,2 & 12,9 & 12,5 & 12,2 & 12,7 & $9,0-14,0$ \\
C18:0 & 0,3 & 0,2 & 0,3 & 0,2 & 0,3 & 0,3 & $<0,5$ \\
C18:1 & 4,8 & 5,4 & 5,0 & 5,2 & 4,8 & 5,1 & $0,5-4,0$ \\
C18:2 & 32,9 & 32,2 & 33,0 & 34,0 & 33,0 & 33,0 & $24,0-42,0$ \\
C18:3 & 49,1 & 48,2 & 48,6 & 47,7 & 49,3 & 48,6 & $34,0-62,0$ \\
Total AGS & 0,3 & 0,3 & 0,3 & 0,3 & 0,3 & 0,3 & $<2,0$ \\
Total AGI & 17,4 & 19,0 & 17,91 & 17,7 & 17,0 & 17,7 & - \\
Índice de iodo & 82,6 & 81,0 & 82,1 & 82,3 & 83,0 & 82,1 & - \\
calculado & 114,4 & 112,3 & 113,5 & 112,9 & 114,7 & 113,5 & $103-128$ \\
\hline
\end{tabular}

C16:0-ácido palmítico; C16:1-ácido palmitoléico; C18:0-ácido esteárico; C18:1-ácido oléico; C18:2-ácido linoléico; C18:3-ácido linolênico

* - Codex Alimentarius (faixa de valores aplicada para o óleo de milho comestível). AGS - ácidos graxos saturados.

$A G I$ - ácidos graxos insaturados. 
cultivada na Amazônia. (Franco, 1992; Guitierez et. al., 1997; Nery, 1969 ).

A fração oleosa e o indice de iodo calculado $(113,5)$ revelaram um perfil de ácidos graxos semelhantes, também, ao do óleo de milho comestivel (Tab. 2), excetuando-se o caso do ácido esteárico (C18:0), que foi superior ao limite máximo aplicado pelo Codex Alimentarius, Dados da literatura (Kaloyeras, 1958), mostram o papel importante do ácido linoléico na perda da viabilidade das sementes, uma vez que a alta insaturação favorece a oxidação lipídica. Acreditava-se que no caso da sapucaia, a casca dura e escura que envolve as amêndoas, amenizaria esse processo. No entanto, o teste de germinação realizado no laboratório de sementes do Instituto Florestal de São Paulo não confirmou esta hipótese, revelando uma percentagem de germinação de $26 \%$, considerada baixa, e evidenciando o pouco poder de germinação e a pouca influência da dureza da casca nesse processo. Este fato sinaliza que novos estudos deverão ser conduzidos para um melhor esclarecimento desse comportamento.

Do ponto de vista vitamínico, a vitamina C $(17,10 \mathrm{mg} / 100 \mathrm{~g})$ apresentou indice elevado quando comparado ao da castanha do pará $(10,3 \mathrm{mg} / 100 \mathrm{~g})$, citado por Franco (1992). Quanto à vitamina $\mathrm{B} 1$, os valores encontrados para a sapucaia foram inferiores aos referidos para a castanha-do Pará $(0,31$ e $1,09 \mathrm{mg} / 100 \mathrm{~g}$, respectivamente), enquanto para a Vitamina B2 foram superiores, ou seja : 0,25 e $0,12 \mathrm{mg} /$ $100 \mathrm{~g}$, respectivamente (Franco, 1992).

Complementarmente, determinou- se os minerais presentes nas amêndoas (Tab. 3), destacando-se entre os macronutrientes, os elevados teores de $\mathrm{Na}, \mathrm{K}$ e B (faixa de 45,0 a $65,0 \mathrm{mg} / \mathrm{g}$ ) e para os micronutrientes, os elementos Fe $(14,2 \mu \mathrm{g} / \mathrm{g})$ e Mn $(91,0 \mu \mathrm{g} / \mathrm{g})$. Do ponto de vista fisiológico, a deficiência dos alimentos $\mathrm{Na}$ e K e dos catalisadores Fe e $\mathrm{Mn}$, nos processos bioquímicos (De Angelis, 1977), comprometem as funções metabólicas nos organismos vivos.

Tabela 3. Composição dos elementos inorgânicos presentes nas amêndoas de sapucaia.

\begin{tabular}{cc}
\hline Elementos & Teores $^{*}$ \\
\hline $\mathrm{Mg}$ & $1,55 \pm 0,11$ \\
$\mathrm{Ca}$ & $1,11 \pm 0,15$ \\
$\mathrm{Na}$ & $49,8 \pm 0,33$ \\
$\mathrm{~K}$ & $46,4 \pm 0,21$ \\
$\mathrm{~B}$ & $64,5 \pm 0,25$ \\
$\mathrm{As}$ & $(\mu \mathrm{g} / \mathrm{g})$ \\
$\mathrm{Fe}$ & $0,28 \pm 0,16$ \\
$\mathrm{Mn}$ & $14,2 \pm 0,21$ \\
$\mathrm{~Pb}$ & $91,0 \pm 0,36$ \\
$\mathrm{Se}$ & $0,96 \pm 0,25$ \\
$\mathrm{Al}$ & $0,28 \pm 0,12$ \\
$\mathrm{Sn}$ & $4,91 \pm 0,13$ \\
\hline
\end{tabular}

* - média de três repetiçôes e respectivos desvios - padrões

Dentre os elementos encontrados e considerados tóxicos, destacou-se o $\mathrm{Pb}$ $(0,96 \mu \mathrm{g} / \mathrm{g})$, presente em concentrações bem acima do limite máximo permitido pela legislação brasileira $(0,5 \mu \mathrm{g} / \mathrm{g})$, (BRASIL, leis, decretos, etc. 1990), demostrando que a amostra poderá causar uma possivel toxicidade se empregada na alimentação humana e de animais silvestres (Cavalcante, 1996), evidenciando uma provável contaminação antrópica no local amostrado (Município de Santa Rita do PassaQuatro). Este dado torna-se relevante quando utilizado como indicador da qualidade ambiental desta região, visto que $\mathrm{o} \mathrm{Pb}$ 
pode estar distribuido no meio ambiente, em diversas formas como por exemplo: $\mathrm{Pb}$ metálico, sais e ions de $\mathrm{Pb}$ e compostos organometálicos. No entanto, ele não é fácilmente extraido do solo pela planta e, sua ocorrência é freqüentemente devido à poluição do ar, contaminando a superficie das plantas. $\mathrm{O} \mathrm{Pb}$ não apresenta uma função essencial ao metabolismo animal, mas tem efeitos adversos, incluindo uma neurotoxicidade à niveis de exposição do ar de poucos microgramas $(\mu \mathrm{g})$ e, na faixa de $15-100 \mu \mathrm{g}$ quando presente nos alimentos.

Embora este fato comprometa o aproveitamento dessas sementes como fonte alimentar, esta informação não invalida o seu valor nutricional, visto que pode se trata de um problema localizado de poluição química, podendo não acontecer em outras regiões do Brasil, aonde essa espécie ocorre.

Com relação à presença do $\mathrm{Al}$, não há relatos de uma função essencial deste mineral nos organismos vivos. No entanto, sabe-se que os compostos de $\mathrm{Al}$ são pouco absorvidos pelas plantas através do solo, mas esta absorção pode ser aumentada através do aumento da acidez do solo causada pela chuva ácida. Além disso, existe uma relação ainda não bem estabelecida, entre o $\mathrm{Al}$ e a doença de Alzheimer no homem.

\section{CONCLUSÕES}

As amêndoas de Lecythis pisonis Camb. (sapucaia) apresentaram altos teores lipídicos e protéicos, o que poderia constituir-se em uma boa fonte calórica para a dieta alimentar de uma população com baixo teor nutricional;

Os teores lipídicos, proteícos da semente de sapucaia e a composição dos ácidos graxos do óleo das amêndoas foram semelhantes aos referidos para a castanha-do-Pará (Bertholletia excelsa).

A fração oleosa das amêndoas revelou um perfil de ácidos graxos semelhante, também, ao do óleo de milho comestível, com predominância para o ácido linoléico, ácido graxo essencial para a alimentação;

$\mathrm{O}$ elevado teor lipidico e a insaturação do óleo da amêndoa da sapucaia, favorece a possível utilização na indústria de óleos comestiveis;

O alto grau de insaturação dos ácidos graxos pode conferir ao óleo da sapucaia, uma alta suscetibilidade a processos oxidativos;

As amêndoas da espécie estudada apresentaram ainda, um alto teor de vitamina $\mathrm{C}$, quando comparadas com as da castanha-do-Pará e,

Os elevados teores de $\mathrm{Pb}$ evidenciam uma possivel toxicidade da amostra para fins alimenticios e uma provável contaminação antrópica do local amostrado, sugerindo ainda que novos estudos devem ser realizados com amostras provenientes de outras regiões do Brasil.

\section{AGRADECIMENTOS}

Agradecemos a valiosa colaboração dos Srs:

Norberto Camilo Campos, bolsista do Instituto Adolfo Lutz, na Seção de Óleos, Gorduras e Condimentos;

Everaldo de Cerqueira, técnico de laboratório da Seção de Química Biológica do Instituto.Adolfo Lutz;

Antonio Roberto Ferreira, da 
Seção de Fotomicrografia do Instituto Adolfo Lutz;

Benedito Lopes da Silva, técnico de Apoio à Pesquisa Cientifica e Tecnológica da Seção de Silvicultura do Instituto Florestal de São Paulo;

A Seção de Silvicultura do Instituto Florestal de São Paulo, pela doaçâo dos frutos para estudo;

Ao Dr Rui Feifer, Pesquisador Cientifico do Instituto Florestal, pela correção e sugestões na elaboração do texto, e

Ao Sr. Silvestre Silva pela autorização da reprodução de fotografias de sua propriedade.

\section{Bibliografia Citada}

Aguiar, I.B. de; Pinã-Rodrigues, F.C.M. ; Figliolia, M.B. 1993. Sementes Florestais Tropicais. Brasília, D.F. Abrates. 350p.

American Oil Chemists' Society.1990 Official methods and recommended practice of the American Oil Chemists' Society. $4^{\text {th }}$ ed.Champain, A.O.C.S., (A.O.C.S. Recommended Pratice Cd 1c-85).

Brasil, Leis, decretos, etc.-Portaria N ${ }^{\circ} 16 / 90 \mathrm{da}$ Divisão Nacional de Vigilância Sanitária de Alimentos (DINAL), Diário Oficial. Brasilia, 15 mar.1990. Seç. I, pt.I, p.5436. Autoriza a inclusão, na Tabela II do Decreto $\mathrm{N}^{\circ} 55.871$, de 26 de março de 1965, dos limites máximos de tolerância de chumbo $(\mathrm{Pb})$ em alimentos.

Brasil. Ministério da Agricultura.1992. Regras para análise de sementes Brasília.365p.

Cavalcante, P.B. 1996. Frutas comestiveis da Amazônia. $6^{\circ}$ ed. Belém, Museu Paraense Emílio Goeldi. p.82-84, 209-210. (Coleção Adolpho Ducke).

Codex Alimentarius Commission.1993. Fats, oils and related products. 2 nd ed, Rome, $\mathrm{FAO} /$ WHO, v.8, p.29 [CODEX STAN 25 1981].

Contreras-Guzman, E.; Strong III, F.C.\& Guernelli, O. 1984. Determinação de ácido ascórbico (vitamina C), por redução de ions cúpricos.Quimica Nova, São Paulo, 7 (2):60-64.

De Angelis, R.C. 1977. Fisiologia da nutrição; fundamentos para nutrição e para desnutrição. São Paulo, EDART. Ed..da Universidade de São Paulo, v.1, cap 4,, 320p.

Franco, G.1992. Tabela de composição quimica dos alimentos. $9^{a}$ ed. Rio de Janeiro, São Paulo, Atheneu, p.78, $121,147,302$.

Façanha, J.G.V.; Varela, V.P. 1986/87. Resultados preliminares de estudos sobre a conservação e composição bioquimica de sementes de copaíba (Copaifera multijuga Hayne)-Leguminosae. Acta Amazonica, 16/17 ( $\mathrm{N}^{\circ}$ único):377-382.

Freire, R. M. M.; Santos, R.C.dos ; Beltrão, N. E.de M. 1996 Qualidade nutricional e indústrial de algumas oleaginosas herbáceas cultivadas no Brasil. Óleos \& Grãos, Ano V, (28): 49-53.

Goldman, G.H.; Goldman, M.H de S.; Aguiar, J.P.L. 1986/87. Estudo sobre a germinação de sementes de marupá (Simaruba amara Aubl.).I Composição quimica e curva de embebição das sementes; germinação em diferentes temperaturas. Acta Amazonica, 16/17 ( $\mathrm{N}^{\circ}$ único): 383-392.

Gutierrez, E.M.R.; Regitano-D'arce, M.A.B.; Rauen-Miguel, A.M.O. Estabilidade oxidativa do óleo bruto de castanha do pará (Bertholletia excelsa). Ciênc. Tecnol. Aliment. , 17 (1): 22-27, jan.-abr 1997.

Hiane, P.A.; Ramos, M.I.L.; Ramos Filho, M.M. ; Pereira, J.G,, 1992. Composição centensimal e perfil de ácidos graxos de alguns frutos nativos do Estado de Mato Grosso do Sul. Bol.CEPPA, 10 (1):35-42.

Instituto Adolfo Lutz. 1985. Normas Analiticas do Instituto Adolfo Lutz. v.1; métodos químicos e físicos para análise de alimentos. $3^{\text {a }}$ ed. São Paulo, p.21-24, 266, $378-404$.

Kaloyeras, S.A., 1958. Rancidity as a factor in the loss of viability of pine and other seeds. J.Am.Oil Chem Soc., 35:176-179.

Manual Rapid Digestion System MX-350 
Spex. 1991.[Método 209].

Mori, S.A.; Prance, G.T. 1990 LecythidaceaeMonograph 21(II). Flora Neotropica, part II, 295-297.

Nery, J.P. Castanha-do-Pará, Bol ITAL, 20:1325,1969

Vallilo, M.I.; Tavares, M; Aued.S. 1990. Composição química da polpa e da semente do fruto do cumbaru (Dipteryx alata Vog.)- Caracterização do óleo da semente. Rev.Inst. Flor., São Paulo, 2(2): $115-125$. 